\title{
Paulo Freire e Edgar Morin: combatentes da esperança e da utopia por um mundo novo possível
}

\author{
Izabel Petraglia* \\ MariangelicaArone**
}

\section{Resumo}

Em momento de grandes mudanças que nos apontam para uma crise humanitária em dimensões planetárias, celebramos em 2021 o centenário de nascimento de Paulo Freire e Edgar Morin, dois pensadores progressistas que nos apontam para a importância de uma reforma de pensamento que pressupõe uma práxis ecologizada. Esse estudo bibliográfico tem por objetivo refletir sobre pontos de convergência entre os dois autores. Iniciamos apresentando dados específicos sobre a vida e a obra de Freire e Morin e, em seguida indicamos e refletimos sobre aspectos relevantes de convergência entre eles, tais como: politização do pensamento, inacabamento do ser humano, a noção de dialogia, o erro na construção do conhecimento, problematização e contextualização do conhecimento, amorosidade na educação e na vida, opressão, violência, tirania, transformação ou metamorfose. Concluímos ao considerar, a partir das ideias dos autores, que esperança e utopia são possibilidades de transformações sociais e planetárias, que passam pela Educação.

Palavras-chave: Paulo Freire, Edgar Morin, Educação libertadora, Pensamento Complexo, Esperança.

* Doutora em Educação pela USP com Pós-Doutoradopelo Centre Edgar Morin - EHESS/CNRS - Paris - France, Professora Titular do Programa de Pós-Graduação em Educação - PPGE,e líder do GEPEC - Grupo de Estudos e Pesquisa em Complexidade, da Universidade Metodista de São Paulo - UMESP. izabelpetraglia@terra.com.br e https://orcid.org/00000002-9003-8998

** Pós-doutoranda no PPGE, da Universidade Metodista de São Paulo. Doutora em Educação pela UNINOVE. Professora Universitária e Pesquisadora do GEPEC - Grupo de Estudos e Pesquisa em Complexidade. angelicarone@yahoo.com.br e https://orcid.org/ 


\section{falta título em ingles}

\section{Abstract}

At a time of great changes that point us towards a humanitarian crisis in planetary dimensions, in 2021 we celebrate the centenary of the birth of Paulo Freire and Edgar Morin, two progressive thinkers who point us to the importance of a reform of thought that presupposes a greened praxis. This bibliographic study has as its objective to reflect about points of convergence between the two authors. We begin/ start by presenting specific data about the life and work of Freire and Morin, and then we indicate and reflect about the relevant aspects of convergence between them, such as: politicization of thinking, unfinished human beings, the notion of dialogue, the error of knowledge construction, problematization and contextualization of the knowledge, lovingness in education and in live, oppression, violence, tyranny, transformation or metamorphosis. We conclude by considering, based on the author's ideas, that hope and utopia are possibilities for social and planetary transformations, which pass through Education.

Key-words: Paulo Freire, Edgar Morin, Liberating Education, Complex Thinking, Hope.

\section{falta título em espanhol}

\section{Resumen}

En un momento de grandes cambios que nos apuntan hacia una crisis humanitaria a escala planetaria, en 2021 celebramos el centenario del nacimiento de Paulo Freire y Edgar Morin, dos pensadores progresistas que nos señalan la importancia de una reforma del pensamiento que presupone una praxis verde. Este estudio bibliográfico tiene como objetivo reflexionar sobre los puntos de convergencia entre los dos autores. Comenzamos presentando datos específicos sobre la vida y obra de Freire y Morin, para luego señalar y reflexionar sobre aspectos relevantes de la convergencia entre ellos, tales como: la politización del pensamiento, el ser humano incompleto, la noción de diálogo, el error en la construcción. del saber, problematización y contextualización del saber, amor en la educación y en la vida, opresión, violencia, tiranía, transformación o metamorfosis. Concluimos considerando, a partir de las ideas de los autores, que la esperanza y la utopía son posibilidades de transformaciones sociales y planetarias, que pasan por la Educación. Palabras clave: Paulo Freire, Edgar Morin, Educación liberadora, Pensamiento complejo, Esperanza. 
Porque a vida, só é possível reinventada.

(MEIRELES, 1987. p. 116)

\section{Introdução}

As mudanças ocorridas na sociedade contemporânea, principalmente com a disseminação do coronavírus, em 2019, - pandemia que parou o mundo -, colocaram os nossos planos entre a espera e a esperança. Mas, também estabeleceram novas formas de compreender as intrínsecas relações entre pensamento científico, econômico, político, ecossistema e comunidades humanas.

A percepção de mundo nos tempos atuais, nos provoca a interpretar o passado, e a ressignificar o presente, por meio do qual nós questionamos o futuro crísico e incerto. $\mathrm{O}$ presente nos convida a concordar com Caetano Veloso, quando afirma que "Alguma coisa está fora da ordem, Fora da nova ordem mundial". A mundialização que ampliou as comunicações entre povos e nações, ainda não foi capaz de promover a religação de solidariedades dispersas, incipientes ou até inexistentes.

Mas, porque cremos em possibilidades de metamorfose e enfrentamento de uma megacrise humanitária nos diversos campos e cantos do planeta que, esse texto se justifica, no sentido de pensar sobre a necessidade de uma reforma de pensamento que pressupõe uma práxis ecologizada. Entendemos que a Educação seja a brecha capaz de estabelecer novos olhares e ações emergentes para os desafios que se colocam no aqui e no agora, para chegarmos ao futuro com o humanismo regenerado!

Esse estudo bibliográfico se propõe, então, a refletir sobre ideias de dois pensadores, Paulo Freire e Edgar Morin, humanistas planetários, a partir de suas respectivas propostas de Educasaão Libertadora e, Pensamento Complexo, no ano em que o mundo celebra o centenário de seu nascimento. Embora os dois autores nunca tenham se encontrado e tenham vivido em lugares diversos, reco-

\footnotetext{
1 VELOSO, C. Fora da ordem. CD Circuladô, Gravadora: Elektra Nonesuch,1991.
} 
nhecemos convergência em seus pensamentos. Apontaremos aqui, alguns aspectos fundamentais sobre vida e obra e em seguida, destacaremos ideias em comum.

Com obra monumental, ambos foram amplamente traduzidos em vários idiomas. Da mesma geração de 1921, nasceram em um período marcado pelo hiato entre duas grandes guerras mundiais. Eles cursaram Direito e, embora não o tenham exercido, profissionalmente, isso já apontava para as suas preocupações com justiça social e direitos humanos. Ao longo da vida, sempre se posicionaram a favor dos marginalizados e oprimidos e valorizaram uma cidadania, em que todos os humanos, comunitariamente, pertencem a Terra e têm o direito de viverem dignamente e, em liberdade.

\section{O educador da libertação}

Paulo Reglus Neves Freire foi um educador com o compromisso de educar para transformar a realidade. Nasceu no Recife, capital de Pernambuco, Brasil, em 19 de setembro de 1921, faleceu em 02 de maio de1997 na cidade de São Paulo, onde já havia sido Secretário Municipal da Educação, de 1989 a 1991, na primeira gestão municipal do Partido dos Trabalhadores. Foi agraciado com o título de Patrono da Educação Brasileira por meio da Lei 12.612, de 13 de abril de 2012, além de ter recebido inúmeros títulos de Doutor honoris causa, prêmios nacionais, internacionais, reconhecimentos e homenagens.

Ao longo da vida, carregou a sua origem nordestina e a experiência com a fome no período da infância, o que o levaria a se preocupar com os mais pobres. Construiu um método revolucionário de alfabetização, que não só ensinava a ler e a escrever em algumas horas como também era comprometido com a educação emancipadora, em que o sujeito se liberta e ao se libertar, se torna consciente para transformar a si e a sociedade, no sentido de alcançar justiça social.

É do ponto de vista de quem se conecta com os mais frágeis que Freire escreve "Pedagogia do Oprimido", lançado em 1968, a sua principal obra, dentre inúmeras que publicou. Nela, o autor 
defende a importância da educação para os excluídos da sociedade, pois, só com acesso à formação é possível libertar as pessoas mais vulneráveis das condições difíceis que o sistema impõe. Nos deixou importante legado para a "leitura e transformação do mundo".

Freire sob a perspectiva da educação como prática da liberdade apresenta uma pedagogia emancipadora em contraposição ao que ele denominou de "concepção bancária" em educação. Inicialmente, ele se destacou com a proposta para a alfabetização de adultos, mas suas ideias o colocaram no patamar dos grandes filósofos da Educação não só no Brasil, mas no mundo.

\section{$\mathrm{O}$ arquiteto do pensamento complexo}

Edgar Nahoum, pseudônimo de Morin, de origem judaica sefardita, mudou de nome como os cristãos novos, em decorrência das perseguições nazistas ocorridas na Europa, desde os anos de 1490. Ele nasceu em Paris, França, em 08 de julho de 1921 e em 2021 têm sido inúmeras as homenagens, em todo o mundo, em torno de seu aniversário de 100 anos, momento em que nos brinda com lucidez, afeto, sabedoria.

Autor de uma obra, com de mais de 90 livros publicados, incluindo "O método", em 6 volumes, Morin elaborou a epistemologia da complexidade que, extrapolou áreas de formação, numa religação de seres e saberes, unindo o que foi artificialmente separado pelo pensamento fragmentado, simplificado, unidimensional e hiperespecializado. Reconheceu o desafio de conviver com as incertezas, mas, indicou a Educação como reserva antropológica de resistência e transformação como nova via para o futuro da humanidade.

Ao longo de seus 100 anos, dedicou-se aos estudos da antropologia, sociologia, política, filosofia, biologia, cinema. Escreveu e manifestou-se sobre os diversos conflitos que acompanhou e vivenciou nos séculos XX e XXI, tais como a segunda guerra mundial, em que foi combatente voluntário da resistência francesa, contra o nazismo, participou durante dez anos do Partido Comunista e, depois foi expulso por não concordar com o dogmatismo 
stalinista. Posicionou-se politicamente por ocasião da guerra da Argélia, sobre Israel e Palestina, as atrocidades pactuadas por ditadores mundiais, os horrores no mundo islâmico, os ataques terroristas em tempos mais recentes. Enfim, Morin é contra "todas as formas de ditadura, sejam de esquerda, sejam de direita”.

Sua obra e sua vida são entrelaçadas e inseparáveis. Ele navega pelas diversas áreas do saber e, nos mostra que é um estudante permanente e um pesquisador aberto às influências do mundo, já que compreende o ser humano em sua condição de inacabamento e complexidade. Atesta a inseparabilidade da tríade sociedade-indivíduo-espécie, discute a lógica ordem-desordem-interações-organização e destaca do cérebro humano, operadores cognitivos hologramático, recursivo e dialógico, como responsáveis pela elaboração do pensament. Morin aposta na reforma de pensamento - do linear ao complexo - e em uma democracia cognitiva que nos incitam a refletir sobre a necessidade de mudarmos de "Via" para transformar o futuro e salvar o planeta. O pensador entende ainda que, como cidadãos planetários precisamos construir uma política civilizacional, já que habitamos a "Terra-Pátria" e "fazemos parte da mesma comunidade de origem e de destino".

Morin aponta dois pilares fundamentais da ética: responsabilidade e solidariedade, protagonistas de uma necessária regeneração do humanismo que pressupõe amor e fraternidade no enfrentamento de grandes desafios da humanidade, inclusive e sobretudo nos tempos de um futuro próximo, pós-pandemia.

De diversos pontos de convergência entre as ideias de Paulo Freire e Edgar Morin, destacamos a seguir, aspectos que nos parecem mais relevantes, a partir da obra dos dois autores e, o quê, nosso estudo foi capaz de captar.

\section{Politização do pensamento}

Essa ideia, de antemão, já sugere que os autores veem no mundo, um processo de aprendizagem que incorpora ideologias e visões de mundo. Trata-se da problematização da realidade, cons- 
truída na ação-reflexão-ação dos sujeitos humanos sobre o mundo e marcada por uma perspectiva de conscientização. Essa perspectiva refere-se à atitude em que as expressões força, resistência e luta, parecem contagiar o indivíduo com o desejo de conscientizar a si próprio, naquilo que diariamente vestimo-nos da roupa da vida. Essa ideia é transmitida por Freire quando nos diz: "[...] uma forma de... auto-reflexão que as levará ao aprofundamento conseqüente de sua tomada de consciência e de que resultará sua inserção na História, não mais como espectadoras, mas como figurantes e autoras" (1997, p.43). Na mesma direção, considera Morin, que: "Interrogar a nossa condição humana implica questionar primeiro nossa posição no mundo (MORIN, 2000a, p. 47). O que consiste num interrogar-se a si mesmo, constantemente e jamais indiferente aos diversos olhares da realidade.

A politização do pensamento, nos leva a refletir sobre aquilo que realizamos para os outros, voluntariamente. Mais do que ver o outro como um ser no mundo, é necessário compreendê-lo, a partir de uma realidade feita de nuances diversas. O ser humano tem uma presença cingida e descortinada pelo seu mundo e o do outro. E nessa possibilidade nos encontramos na aventura de tecer a vida com fios diferentes, cujo tecido é reforçado por resistência, intervenção, avaliação, constatação, decisão, rompimento, transformação. A politização do pensamento é a constatação da intencionalidade expressa por meio da práxis.

O homem se tornou presente no mundo, envolveu-se com o mundo, com os outros, mesmo, com o desejo de criar, alçar voos, construir-se e construir um caminho. Nessa ideia entra o nosso modo de estar no mundo, a nossa leitura sobre o mundo mediatizada pela realidade, como afirma Freire:

O fato de me perceber no mundo, com o mundo e com os outros me põe numa posição em face do mundo que não é de quem nada tem a ver com ele. Afinal, minha presença no mundo não é a de quem a ele se adapta, mas a de quem nele se insere. (1996, p. 23). 
Essa noção vai ao encontro do que Morin e Kern, premonitoriamente, já sinalizaram no ano de 1973, quando publicaram o livro Terra-Pátria: "A tomada de consciência de nossas raízes terrestres e de nosso destino planetário é uma condição necessária para realizar a humanidade e civilizar a Terra" (2000, p. 105). E, Morin, ainda com outros autores, já nos indicava a Educação como brecha de um caminho viável:

A missão da educação para a era planetária é fortalecer as condições de possibilidade da emergência de uma sociedade-mundo composta por cidadãos protagonistas, consciente e criticamente comprometidos com a construção de uma civilização planetária (MORIN; CIURANA; MOTTA, 2003, p. 98).

Assim se instaura a necessidade da ética nas relações, se impõe a responsabilidade na difícil experiência de manter equilíbrio entre o que se pode obter da vida e a inspiração cúmplice de sonhos e utopias, ao juntar retalhos de um pensar global e um agir local, no encontro de uma política de complexidade, manifesta na diversidade de dimensões inter-relacionadas.

\section{Inacabamento do ser humano}

A definição de inacabamento, sob viés freiriano, constata: “o inacabamento do ser ou sua inconclusão é próprio da experiência vital. Onde há vida, há inacabamento" (FREIRE, 1996, p.55). Na análise empreendida por Freire destaca-se os aspectos da incompletude, como próprios da essência da vida, e a questão é abordada relacionando-a com o duplo, como inconclusa e inacabada. Além da vida, a realidade, a educação, são igualmente, inacabadas e inconclusas. Assim, para o autor: "A educação crítica considera os homens como seres em devir, como seres inacabados, incompletos em uma realidade igualmente inacabada e juntamente com ela" (FREIRE, 1979, p. 42).

A formulação da noção de inacabamento por Morin considera que:" O pensamento complexo está animado por uma tensão permanente entre a aspiração a um saber não parcelado, não dividi- 
do, não reducionista e o reconhecimento do inacabado e incompleto de todo conhecimento" (MORIN; CIURANA; MOT'TA, 2003, p. 54). Para Morin, o inacabamento é entendido como processo contínuo de aprendizagem da e pela condição humana. Aí se coloca a ideia de que o homem está num movimento permanente de se construir e reconstruir, de se conhecer, aprender, cultivar-se e se transformar, durante toda a vida. Morin indica nesse processo, ainda a perspectiva ética de autoanálise e autocrítica (2005) que o acompanham por toda a existência.

Ainda Morin, por meio do conceito de auto-eco-organização, apresenta a expressão da indissociabilidade entre sujeito e mundo, com os quais estão imbricados os operadores cerebrais, responsáveis pela elaboração do pensamento humano: hologramático (em que a parte está no todo, mas o todo também está na parte), recursivo (uma ação age sobre uma causa que, retroage sobre outra ação e, sucessivamente, como um espiral), dialógico (ideias opostas e complementares, cujo conflito não se resolve). Assim, o sujeito está no mundo como também o mundo está no sujeito, numa tríade inseparável: sociedade-indivíduo-espécie.

Entende-se, portanto, que o ser humano se organiza conforme se relaciona com o ambiente em que vive, e isso tem por consequência, o efeito que o contexto tem sobre o seu jeito de viver e vice-versa. Dessa maneira, emergem os conceitos de autonomia e dependência, empregados por Morin do ser/indivíduo, capaz de suprir as suas próprias necessidades, relativamente, enquanto sujeito autônomo, porém dependente do sistema que o cerca. "Para manter sua autonomia, qualquer organização necessita da abertura ao ecossistema do qual se nutre e ao qual transforma" (MORIN; CIURANA; MOTTA, 2003, p. 36).

Já, Freire expressa a condição autônoma como circunstância em que se encontra a ética e a responsabilidade, que são evidenciadas num sentido que "É práxis, que implica na ação e na reflexão dos homens sobre o mundo para transformá-lo" (Freire, 1987, p. 67). O autor corrobora essa afirmação quando afirma: “É com 
ela, a autonomia, penosamente construindo-se, que a liberdade vai preenchendo o "espaço" antes "habitado" por sua dependência. Sua autonomia que se funda na responsabilidade que vai sendo assumida" (FREIRE, 1996, p. 37).

É, portanto, por meio do binômio autonomia-dependência que os autores entendem que o indivíduo se distingue do outro em sua objetividade e subjetividade e, a partir da reflexão consciente transforma a realidade.

\section{A noção de dialogia}

Para Freire (1996, p. 17), "que não seja comunicação e intercomunicação e que não se funde na dialogicidade". Essa ideia notabiliza a expressão do diálogo em suas múltiplas dimensões: igualitária, solidária, cultural, e ao mesmo tempo, significativa e transformadora para que estejam presentes na dialogicidade. A perspectiva de diálogo é evidenciada mais do que na simples existência de duas ou mais pessoas que trocam ideias, munidas pelo compromisso de falar e escutar, mas, pelo estabelecimento de um espaço de confiança e liberdade, numa atmosfera em que erros e acertos, encontros e desencontros são respeitados.

Em seu compromisso dialógico, o professor por exemplo, pode ir além do discurso, com problematização, reflexão, curiosidade a cada passo de sua prática educativa. $\mathrm{O}$ diálogo não é um método ou uma proposta didática, mas, é o próprio compromisso do professor com a educação e a atmosfera que ele cria quando está no exercício do processo de ensino-aprendizagem contextualizado e em interação permanente. $\mathrm{O}$ termo dialogicidade, em Freire acontece por meio do diálogo, na interação e na comunicação com o mundo, para produzir sentido em nossas escolhas, opções.

Quando estamos em diálogo observamos o que Freire, Gadotti e Guimarães (1995), retratam sobre reflexões nas escolhas, concordâncias e discordâncias, as quais nos levam a produzir alternativas, ainda que se mantenha o conflito. Os autores, expressam-se, considerando a prática educacional freireana:

[...] buscávamos mostrar como diálogo e o conflito se articulam como 
estratégia do oprimido. Sustentamos que o diálogo se dá entre iguais e diferentes, nunca entre antagônicos. Entre esses, no máximo pode haver um pacto. Entre esses há é o conflito, de natureza contrária ao conflito existente entre iguais e diferentes. (FREIRE, GADOT'TI \& GUIMARÃES, 1995, p.9).

Em meio a um processo de humanização é essencial o diálogo para a construção de uma escola mais humana e dialógica, em que os diferentes sujeitos em interação possam concordar ou discordar, mas o fundamental é colocar-se em movimento para refletir conjuntamente sobre as múltiplas possibilidades para transformar-se e transformar o mundo.

De acordo com Morin, a expressão dialogicidade guarda o sentido de opostos, concorrente e até antagônicos, com contradições insuperáveis. A complexidade promove a manutenção e não a resolução do conflito e considera o sentido do funcionamento das forças contrárias e complementares, para o enfrentamento do que surge na realidade coletiva. Mais do que a superação, a dialógica, em Morin, pressupõe o enfrentamento de circunstâncias adversas. Trata-se da "unidade complexa entre duas lógicas, entidades ou instâncias complementares, concorrentes e antagônicas que se alimentam uma da outra, se completam, mas também se opõem e combatem." (MORIN, 2005, p. 300). O autor entende que: "O princípio dialógico permite-nos manter a dualidade no seio da unidade. Associa termos ao mesmo tempo complementares e antagônicos" (MORIN, 1996, p. 107). É também unidade na diversidade e vice-versa, o que Morin denominou de unitas multiplex.

A dialógica para Morin é o que nos permite compreender a condição humana, de maneira não binária, do "isto ou aquilo", mas considera o "e" conjuntivo que integra "isto e aquilo", já que o ser humano é, ao mesmo tempo, racional e afetivo, e essa dualidade depende da ordem (razão) e desordem (afetividade) para que ele constitua a sua subjetividade, no processo auto-eco-organizador .

Para melhor compreensão do que entendemos por dialógica, em Morin, é relevante retornarmos à lógica dialética, que se 
dá na ação-reflexão-ação, no ir e vir constante do movimento da vida, que acolhe os momentos de tese, antítese e síntese. Aí, ao se chegar à síntese, ocorre a superação da contradição, o tempo da positividade, da resolução do conflito. Esse movimento possibilita ainda, a formulação de novas teses, novos contrários e a busca de novas perspectivas de superação. Mas, a partir da dialética, Morin, propõe a ideia de dialógica, ou seja, se na dialética há um desfecho, uma transformação, na realidade complexa é desencadeada a força dos contrários, contradições insuperáveis, portanto, a manutenção e não a resolução do conflito que, se mantem na existência.

Embora os autores tratem diferentemente do conceito, as ideias convergem. Paulo Freire parte do diálogo para a ação relacionada à práxis transformadora, mas também construiu junto com Moacir Gadotti, a "Pedagogia do Conflito", que favorece a problematização, a pergunta, a curiosidade do estudante, promovendo assim, a preservação do conflito no contexto educativo. Morin ao entender a dialógica como a insuperabilidade das contradições, supõe também não haver síntese, mas a sua manutenção na polaridade com a análise, que são inseparáveis. Na dialógica moriniana, há a ecologia da ação, em que, muitas vezes, uma ação escapa do controle do autor para entrar nas inter-retro-ações que ele produz, que são ao mesmo tempo causadoras e também resultados daquilo que os produz.

\section{O erro na construção do conhecimento}

Freire e Morin em suas reflexões, nos instigam a refletir sobre a presença do erro no processo ensino-aprendizagem, já que a ação humana, seja do docente, seja do estudante está permeada de incertezas. Ao longo da obra, ambos concordam que erro e ilusão são inseparáveis do processo de elaboração do conhecimento.

Morin afirma (2000a, p. 18):

Todo conhecimento comporta o risco do erro e da ilusão. A educação do futuro deve enfrentar o problema de dupla face do erro e da ilusão.

O maior erro seria subestimar o problema do erro; a maior ilusão seria 
subestimar o problema da ilusão. O reconhecimento do erro e da ilusão é ainda mais difícil, porque o erro e a ilusão não se reconhecem, em absoluto, como tais.

Para enfrentar as incertezas, Morin ressalta a importância de a escola reconhecer os erros, as imprecisões e ilusões de todo conhecimento e criar ações estratégicas para o enfrentamento, já que elas elaboram "[...] um cenário de ação que examina as certezas e as incertezas da situação, as probabilidades, as improbabilidades." (MORIN, 2000a, p. 87). É importante frisar, que o erro deve ser compreendido como uma oportunidade de aprendizagem e avanço intelectual, mesmo entendendo que todo o conhecimento contém riscos (MORIN, 2000a; 2000b).

A escola que hoje ensina muitas certezas, precisa educar também para as incertezas, já que elas fazem parte da vida e o futuro é incerto. Vale o educador pensar em ações estratégicas que possibilitem reconhecer erros, ilusões e provisoriedade do conhecimento. Para Morin, a religação transdisciplinar do conhecimento é uma estratégia de romper com a fragmentação das ciências e a separação das disciplinas que hoje, em sociedades cada vez mais complexas, não fazem sentido. Consequentemente, a reforma do pensamento - do linear ao complexo - que implica na reforma da Educação e das instituições está na ordem do dia, de todo o processo educativo (MORIN, 2000b).

Para Freire é necessário refletir sobre o erro, fruto da avaliação da aprendizagem, que se dá em termos das respostas dos alunos em certo ou errado, se manifestam na educação bancária, concepção que o autor cunhou em sua obra. Para o autor: "Na visão 'bancária' da educação, o 'saber' é uma doação dos que se julgam sábios aos que julgam nada saber." (FREIRE, 1987, p. 67). Seriam esses conhecimentos transmitidos, estáticos e mecânicos. Nessa perspectiva reducionista, o erro é fruto da análise do professor às respostas dos discentes, de maneira a transformar os sujeitos aprendizes em meros recipientes a serem preenchidos, sem o devido valor ao seu poder de criação e criticidade. 
Freire propõe: “[...] pelo ânimo de libertar o pensamento pela ação dos homens com outros na tarefa comum de refazerem o mundo e de torná-lo mais e mais humano". (1987, p. 74), a educação libertadora, para qual o ensino se propõe a provocar a pergunta e desenvolver a curiosidade de aprender. Posição em que alunos e professores interrogam e duvidam do conhecimento cristalizado e das verdades absolutas e buscam um "[...] desenvolvimento da curiosidade crítica, insatisfeita, indócil [...]" (FREIRE, 1996 , p. 35). Mais uma vez, aqui se coloca a dimensão do conflito que se mantem na insatisfação, na incompletude do conhecimento, cuja curiosidade impulsiona o aprendiz para a frente, para a transformação de sua realidade.

Freire ressalta a necessidade de o professor mudar sua postura frente ao erro, e passe a considerá-lo uma "forma provisória de saber” (FREIRE; GADOTTI; GUIMARÃES, 1995, p. 71). Criar situações de aprendizagem abertas, significativas e contextualizadas e colocar o erro como objeto de discussão e percepção dos conhecimentos que o aprendiz traz da sua realidade para as situações formais de aprendizagem, significa abandonar os princípios da educação bancária, bem como o compromisso com a resposta certa, pois, "Esse processo de reprodução de respostas fabrica a "burocratização da mente", obstaculiza a reflexão e a capacidade criadora" (FREIRE e FAUNDEZ, 1985, p. 53).

Assim como Freire, Morin (2000b, 2013a) acredita nas possibilidades criativas e regeneradoras do ser humano. Em diversas passagens de sua obra, Morin afirma que "o que não se regenera, se degenera". E isso serve para o ser humano, para as teorias, para os modos de conhecer o próprio conhecimento.

Para os autores o papel do professor não é corrigir, mas descobrir como foi que o aluno errou, e fazer as intervenções necessárias para que a partir dos erros se oportunize novas situações e recriações na busca da aprendizagem. 


\title{
Problematização e contextualização do conhecimento
}

Entre as ideias dos autores apresentadas até o momento, acreditamos que há mais uma conexão fundamental entre elas: a valorização da realidade do estudante. Em cada ideia discutida, Freire e Morin nos mostram uma preocupação com a problemática do conhecimento, o questionamento e a construção de possibilidades de contextualização. Ambos nos convidam a manter a ideia do movimento no processo de construção do conhecimento, no binômio explicação-problematização, no diálogo com o desconhecido, com a valorização da "leitura do mundo que precede a leitura da palavra" (FREIRE,1997) e os "mares de incertezas, com alguns arquipélagos de certezas" (MORIN, 2000a) que as envolvem.

Freire ressalta a necessidade de partir da realidade do sujeito, de suas experiências de vida e de sua leitura de mundo como ponto de partida para se construir a leitura da palavra (conhecimento), o que os levará à apropriação de saberes e a uma consciência libertadora, isto é, o educando estabelecerá relações de diálogo conscientes com o seu contexto e tempo para resolver situações desafiadoras. A contextualização então do conhecimento passa a ter maior significado para o aluno. O que significa para Freire,

\begin{abstract}
Quanto mais se problematizam os educandos como seres no mundo e com o mundo, tanto mais se sentirão desafiados. Tão mais desafiados, quanto mais obrigados a responder ao desafio. Desafiados, compreendem o desafio na própria ação de captá-lo. Mas, precisamente porque captam o desafio como um problema em suas conexões com outros, num plano de totalidade, e não como algo petrificado, a compreensão resultante tende a tornar-se crescentemente crítica, por isso, cada vez mais desalienada. (1987, p. 70)
\end{abstract}

Tendo em vista esse horizonte crítico que se delineia "a educação problematizadora se faz, assim, um esforço permanente através do qual os homens vão percebendo, criticamente, como estão sendo no mundo com que e em que se acham”. (FREIRE, 1987, p. 72). O autor compreende a problematização como uma maneira de 
provocar a reflexão sobre temáticas pertinentes às questões da vida e da existência humana.

Morin fala de um "saber educativo" (2000b) que parte da problematização do real e da contextualização de conhecimentos pertinentes ao aprendiz (2000a), a discussão dos saberes e das incertezas presentes nos diversos conhecimentos, de modo a contemplar as emergências do tempo e do espaço. Para isso, propõe estratégias para considerar o contexto e o complexo que se elabora na escola. Para Morin (2000b, p.15):

O conhecimento pertinente é o que é capaz de situar qualquer informação em seu contexto e, se possível, no conjunto em que está inscrita. Podemos dizer até que o conhecimento progride não tanto por sofisticação, formalização e abstração, mas, principalmente, pela capacidade de contextualizar e englobar.

O arcabouço do conhecimento pertinente está em “inserir os conhecimentos parciais e locais no complexo e no global sem esquecer as ações do global sobre o parcial e o local" (MORIN, 2013a, p. 198). Nesse sentido, o autor aponta a problematização do conhecimento a ser realizada por educador e educando, de maneira a colocar seus saberes diante da realidade local e refletir e interpretar esses conhecimentos com o mundo que os cerca, um ensino com significado e sentido para a vida. Morin ainda se vale de Montaigne, para afirmar que "mais vale uma cabeça bem-feita" para contextualizar e globalizar o conhecimento, e compreender e solucionar os problemas da vida, "do que uma cabeça bem cheia", que empilha e armazena conteúdos distantes e desconexos (MORIN, 2000b).

Freire e Morin nos provocam a repensar a construção do conhecimento e o papel do professor que ensina e aprende ao religar e assim também promover a religação dos conhecimentos pertinentes e contextualizados.

\section{Amorosidade na educação e na vida}

A amorosidade, para Freire e Morin, provém de suas experiências de vida amorosas, de natureza ética e humanista, que os 
impelem ao respeito ao diverso, a compreensão e ao acolhimento dos seres humanos como irmãos planetários. Trata-se de uma amorosidade firmada no compromisso entre os seres humanos, com base nos sentimentos, desejos, resistência, razão, emoção, respeito.

A amorosidade é o tom empregado para interagir, criar, estabelecer relações e aprender na relação pedagógica, em que aflora o cuidado com o outro, como afirma Freire (1987, p. 51): “[...] se não há um profundo amor ao mundo e aos homens. Não é possível a pronúncia do mundo, que é um ato de criação e recriação [...]", pois a premissa é o amor que se respalda na ação docente, que se faz pelo diálogo e pela escuta sensível.

A amorosidade se dá com comprometimento ético- estético com seres humanos e com a vida, na abertura e no acolhimento do outro que é, ao mesmo tempo, um igual e um diferente. Freire assegura que a amorosidade é fundamental ao ambiente escolar (1996, p. 120):

É preciso que saibamos que, sem certas qualidades ou virtudes como amorosidade, respeito aos outros, tolerância, humildade, gosto pela alegria, gosto pela vida, abertura ao novo, disponibilidade à mudança, persistência na luta, recusa ao fatalismo, identificação com a esperança, abertura à justiça, não é possível a prática pedagógica-progressista.

De acordo com Morin (2019), o movimento constante da vida, é a sabedoria herdada da filosofia de Heráclito (540-470 a.C.) que afirma: "Concórdia e discórdia: pai e mãe de todas as coisas", desencadeados no processo de auto-eco-organização dos sujeitos humanos em que:

Concórdia cria organizações por meio de associações sistêmicas. Discórdia conduz à desintegração desses sistemas, e tudo isso continua e continuará ninguém sabe até quando... Já reiteramos que a vida é um nó górdio inevitável de associações, cooperações, ajudas mútuas e conflitos, predações, antagonismos e incessantes combinações entre vida e morte. Desse modo, a vida obedece à relação indissolúvel entre concórdia e discórdia, que também poderíamos denominar de relação indissolúvel entre Eros, que sempre busca unir, Pólemo que sempre buscar opor, e Tânatos que sempre busca destruir (MORIN, 2019, p.23) 
Morin entende que na disputa entre Tânatos (pulsão de morte) e Eros (pulsão de vida/amor), é preciso escolher Eros. A educação carece de amor nas escolhas do cotidiano em que somos convidados a unir a prosa da técnica à poesia da arte, da metáfora, da filosofia (MORIN, 2019).

Morin e Freire são transgressores de uma ordem positivista estabelecida, que compreendia a ciência como eterna e totalmente objetiva, Os autores questionam a superficialidade das emoções que acontece no seio da academia e da intelectualidade de seu tempo, em que ousaram amar, acima de tudo. Ambos falam e vivem o amor, são apaixonados pela vida! E isso, tivemos a oportunidade de acompanhar ao longo da vida de cada um, tanto por fatos e eventos da vida privada publicizados pela mídia, quanto por seus escritos autobiográficos ou ainda pelo convívio particular entre amigos, daqueles que tiveram o privilégio de desfrutar da amizade de um ou dos dois autores.

Morin, por exemplo, encontrou em Eros a força para sua vida, bem vivida, produtiva e afetivamente, que completou um século. Ele está no quarto casamento, sendo o atual realizado aos 89 anos com uma linda mulher, 40 anos mais jovem, a socióloga marroquina, Sabah Abouessalam, atualmente responsável por uma Fundação francesa, recém-criada em Paris, com o auspicio da Unesco, que tem o objetivo de manter o legado do autor.

Paulo Freire surpreendeu a todos quando se casou com a Nita (Ana Maria Araújo Freire), após intenso sofrimento pela morte de sua primeira esposa Elza Maria Costa, em 1986. Ele enfrentou a tristeza após o reencontro com Nita, sua ex-aluna, com quem se casou em seguida e, ficou casado por 10 anos, até sua morte, em 1997.

Os exemplos de resiliência, afetividade e capacidade de amar tanto de Freire, quanto de Morin nos inspiram e nos marcam como sujeitos em constante aprendizagem e transformação, educadoras comprometidas com a utopia de tempos menos áridos e mais afetivos entre os seres humanos. 


\section{Opressão, violência, tirania}

Embora Paulo Freire e Edgar Morin tenham vivido em contextos históricos distintos, um na França e outro no Brasil, ambos pensadores fazem ecoar de seus princípios, a fraternidade e o engajamento político. Vale destacar que Morin experienciou a perseguição nazista, a Segunda Guerra Mundial na resistência francesa, a expulsão do Partido Comunista. Freire enfrentou a ditadura militar brasileira, a prisão e o exílio. Podemos afirmar que ambos vivenciaram situações de opressão que podem provocar o silenciamento, bem como presenciaram inúmeras violências e tiranias. No entanto, invariavelmente se manifestaram e se expressaram a favor dos invisíveis da história. Freire e Morin são homens que lutaram pela dignidade humana, pela liberdade e contra as injustiças de seu tempo, lugar, com vistas à uma cidadania planetária.

Os pensadores entendem a tríade: opressão, violência e tirania, e todos os termos que ferem a dignidade humana como motivos absolutos de interferência e combate pela Educação, aqui concebida como formação permanente, permeada de valores e práxis comprometida com a transformação da realidade. Ambos os autores entendem que o processo educativo é importante espaço de emancipação e apontam para a educação como caminho de autoconhecimento, conscientização e libertação de qualquer forma de domesticação, provocando-nos para que possamos agir pela transformação da realidade e de nossa condição humana.

A urgência em reformar o pensamento e a educação como espaço de transformação social, nos chama ao compromisso de hominizar-nos e humanizar a humanidade. Neste caminho, o pensamento complexo de Morin, oferece a dimensão de uma antropoética capaz de assumir o destino humano, como via para o movimento de religação da vida, contra a dominação, a opressão e a barbárie (MORIN, 2000a; 2005; 2020)). Isso se refletirá na escola, por meio de "sete saberes necessários à educação" deste século (MORIN, 2000a), que estabelece uma "pedagogia do oprimido" (FREIRE, 1987) e uma "educação como prática de liberdade" (FREIRE, 
1997). Precisamos assim, de um caminho para a realização de experiências, que nos impulsione a viver pela "fraternidade" (MORIN, 2019), justiça e compreensão da condição humana.

Para Morin (2019), fraternidade é "esse meio de resistência contra a crueldade do mundo (...). O objetivo não deve ser um termo, mas tornar-se num caminho, o nosso caminho, o da aventura humana” (p.12). A criação de um "oásis de fraternidade" (MORIN, 2019) é uma forma de resistência, uma revolta pacífica baseada na ajuda mútua, na não violência, na solidariedade, na paz. Para mudar de via precisamos enfrentar a opressão, resistir à barbárie marcada por movimentos de regressão democráticos nacionais e mundiais, despertar para a denúncia e para o anúncio de iniciativas marginais, capazes de se opor à maldade, ao desrespeito e às afrontas aos processos democráticos.

\section{Transformação ou metamorfose}

A urgência de uma reforma de pensamento de que nos fala Morin, ao longo de sua obra, deve vir acompanhada de uma reeducação da educação, com a missão de restaurar novas visões de mundo, a solidariedade, a ética e o humanismo (MORIN, 2020). Freire e Morin viveram em função de um humanismo planetário.

Morin destaca (1997, p. 9):

Minha vida intelectual é inseparável de minha vida, como escrevi em La Méthode: não escrevo de uma torre que me separa da vida, mas de um redemoinho que me joga em minha vida e na vida. Nietzsche dizia: "Sempre expus em meus escritos toda a minha vida e toda a minha pessoa... Ignoro o que possam ser problemas puramente intelectuais”. Não sou daqueles que têm uma carreira, mas dos que têm uma vida.

Paulo Freire afirma (1992, p. 34):

Entre as responsabilidades que, para mim, o escrever me propõe, pra não dizer impõe, há uma que sempre assumo. A de, já vivendo enquanto escrevo a coerência entre o escrevendo-se e o dito, o feito, o fazendo-se, intensificar a necessidade desta coerência ao longo da existência. A co- 
erência não é, porém, imobilizante. Posso, no processo de agir-pensar, falar-escrever, mudar de posição.

Ambos os autores concordam que a mudança começa com atitudes individuais, isoladas. Freire entende que o oprimido ao salvar-se, por meio da conscientização que adquire, acaba salvando também o opressor. E afirma (FREIRE, 1987, p. 52): "Os oprimidos, nos vários momentos de sua libertação, precisam reconhecer-se como homens, na sua vocação ontológica e histórica de ser mais" (Grifo do autor).

Morin entende que iniciativas marginais transformadoras tomam forma e se tornam tendências. Ele não usa a palavra revolução, entendendo se tratar de um termo desgastado e já muito utilizado por pessoas, grupos, movimentos que o utilizaram com objetivos às avessas da emancipação $(2019 ; 2020)$. O autor também prefere a palavra metamorfose à transformação, por entendê-la complexa, multidimensional, que compreende atitudes ecologizadas - ECO vem do grego - oikos, que significa casa, lar, meio ambiente (2002).

Freire e Morin nos indicam que precisamos de um conhecimento problematizado, que seja capaz de relacionar, contextualizar e religar diferentes saberes concebendo uma reforma de pensamento e de ações para a transformação. Ambos tecem críticas ao conhecimento fragmentado, descontextualizado e sem sentido.

Freire afirma (1996, p. 58-59):

[...] Gosto de ser gente porque a História em que me faço com os outros e de cuja feitura tomo parte é um tempo de possibilidades e não de determinismo. Daí que insista tanto na problematização do futuro e recuse sua inexorabilidade.

Morin (2002, p. 19) aponta: "A obsessão principal da minha obra diz respeito à condição humana". E Freire corrobora: “[...] Não é possível fazer uma reflexão sobre o que é a educação sem refletir sobre o próprio homem“ (1982, p. 27).

Dos ensinamentos de Freire e Morin, destacamos que é necessária a revitalização da ética, das ideias, dos conhecimentos, 
das relações, das ações, das finalidades da educação, construídos pela combinação de autonomias individuais, solidariedades comunitárias e responsabilidades com a humanidade. É cada vez mais urgente a formação e autoformação de cidadãos planetários capazes a enfrentar os problemas atuais, de transformar a sociedade e a humanidade para habitar o planeta.

Para isso, Morin entende que é preciso "bem-pensar" (2013b, p. 61):

Para mim, "bem-pensar" significa abandonar os pontos de vista dos saberes separados que não sabem enxergar a urgência e o essencial; significa descompartimentar os saberes, ver o todo nas partes e as partes no todo, esforçar-se em conceber a solidariedade entre os elementos de um todo e, desse modo, contribuir para suscitar uma consciência de solidariedade; conhecer os contextos e reconhecer a complexidade das situações nas quais devemos agir significa, em particular, compreender que existe uma "ecologia da ação" que, com frequência, pode desviar nossas ações de seu sentido desejado e orientá-las até mesmo em sentido contrário, e assim, nossas intenções morais podem chegar a resultados imorais; significa reconhecer e enfrentar incertezas morais e contradições éticas, compreender que nem sempre se pode distinguir facilmente o bem e o mal, saber que nossos deveres éticos com frequência são antagônicos, até mesmo irreconciliáveis, pois temos deveres conosco mesmo, com nossos próximos, com a sociedade, com a espécie, com nossa Terra-Pátria.

Na mesma direção, Freire chama de "pensar certo" (1996, p. 31):

O professor que pensar certo deixa transparecer aos educandos que uma das bonitezas de nossa maneira de estar no mundo e com o mundo, como seres históricos, é a capacidade de, intervindo no mundo, conhecer o mundo. Mas, histórico como nós, o nosso conhecimento do mundo tem historicidade. Ao ser produzido, o conhecimento novo supera outro antes que foi novo e se fez velho e se "dispõe" a ser ultrapassado por outro amanhã1. Daí que seja tão fundamental conhecer o conhecimento existente quanto saber que estamos abertos e aptos à produção do conhecimento ainda não existente. Ensinar, aprender e pesquisar lidam com esses dois momentos do ciclo gnosiológico: o em que se ensina e se aprende o conhecimento já existente e o em que se trabalha a produção do conhe- 
cimento ainda não existente. A "dodiscência" - docência-discência - e a pesquisa, indicotomizáveis, são assim práticas requeridas por estes momentos do ciclo gnosiológico.

A reflexão de Freire sobre o "pensar certo" está relacionada à escola democrática, em que se pratique a reflexão dos conhecimentos pelos alunos e professores e os levem a transformar a si próprios e à sociedade. Para Morin, o "bem pensar" exige abordar os problemas globais e fundamentais, considerando a reforma de pensamento, superando a perspectiva isolada das disciplinas, em que a fragmentação ocorre em parcelas desconectadas e estéreis e a informação é tratada como conhecimento, além intercomunicação de todo e parte que se relacionam e interagem. Isto requer o conhecimento situado em contexto, integrado e em consonância com as condições de sua própria produção. Pensar certo e bem pensar são meios necessários à transformação e ou à metamorfose da sociedade e do mundo.

\section{Considerações finais}

A perspectiva de esperança e utopia, em nosso ponto de vista são as convergências reflexivas mais animadoras que Freire e Morin nos propiciam. Freire (1987), criou o verbo esperançar em alusão à dimensão ativa do fazer para promover - não esperar passivamente que as transformações aconteçam. Trata-se de ter esperança na mudança, mas fazendo, efetivamente. Morin entende que não há esperança que não seja desafio, porque conta com incertezas, mas também com resistências à crueldade do mundo (2020).

Freire cunhou o termo "inédito viável" (1987, 1992) para explicar o novo que ainda não aconteceu, mas que poderá haver um dia. O temos utopia congrega os termos U- não; TOPIA- lugar: o que não tem lugar no presente, mas quem sabe um dia! Morin também entende a esperança como uma aposta e nos convida a distinguir entre duas utopias (MORIN, 2020; NAIR; MORIN, 1997): 1) o melhor dos mundos, que é inviável, 2) um mundo melhor, que é possível, ainda que improvável. 
Um mundo melhor se faz com o fim das guerras, regulação de conflitos, pessoas alimentadas e saudáveis, melhores condições econômico-políticas, justiça social, bem-viver. Bem/viver significa qualidade de vida e não quantidade de bens, respeito às múltiplas diversidades, inclusão do diferente, democracia e voz das minorias.

Concluímos, reforçando as ideias de ação, transformação e resistência dos dois autores, ressaltando a importância de levarmos a cabo as nossas atitudes marginais, que significa aquilo que cada um e todos podemos fazer nas brechas e bifurcações do caminho. Compartilhamos da afirmação de Morin quando afirma que "nada é certo, nem o Pior"! Por isso apostemos no possível, ainda que esse possível seja improvável!

\section{Referências}

FREIRE, P. Educação como Prática da Liberdade. Rio de Janeiro: Paz e Terra, 1997.

FREIRE, P. Pedagogia da autonomia: saberes necessários à prática educativa. Rio de Janeiro: Paz e Terra, 1996.

FREIRE, P. Pedagogia da esperança: um reencontro com a Pedagogia do Oprimido. Rio de Janeiro: Paz e Terra, 1992.

FREIRE, P. Pedagogia do Oprimido. 23. ed. Rio de Janeiro: Paz e Terra, 1987.

FREIRE, P. Educação e mudança. Rio de Janeiro: Paz e Terra, 1982.

FREIRE, P. Conscientização. 3.ed. São Paulo: Cortez \& Moraes, 1979.

FREIRE, P. GADOT'TI, M.; GUIMARÃES, S. Pedagogia: Diálogo e conflito, São Paulo: Cortez, 1995.

FREIRE, P; FAUNDEZ, Antônio. Por uma pedagogia da pergunta. Rio de Janeiro: Paz e Terra, 1985.

MEIRELES, C. Obra poética ou obras completas. Rio de Janeiro: Nova Aguilar, 1987. 
MORIN, E. (com a colaboração de Sabah Abouessalam). É hora de mudarmos de via: as lições do coronavírus. Trad. Ivone C. Benedetti. Rio de Janeiro: Bertrand Brasil, 2020.

MORIN, E. Fraternidade: Para resistir à crueldade do mundo. Trad. Edgard de Assis Carvalho. São Paulo: Palas Athena, 2019.

MORIN, E. Meus filósofos. Trad. Edgard de Assis Carvalho e Mariza Perazi Bosco. Porto Alegre: Sulinas, 2013b.

MORIN, E. A via para o futuro da humanidade. Trad. Edgard de Assis Carvalho e Mariza Perazi Bosco. Rio de Janeiro: Bertrand do Brasil. 2013a.

MORIN, E. O método 6: ética. Trad. Juremir Machado da Silva. Porto Alegre: Sulina, 2005.

MORIN, E. O Método 5: a humanidade da humanidade. Trad. Juremir Machado da Silva. Porto Alegre: Sulina, 2002.

MORIN, E. A cabeça bem-feita: repensar a reforma, reformar o pensamento. Trad. Eloá Jacobina. Rio de Janeiro: Bertrand Brasil, 2000b.

MORIN, E. Os sete saberes necessários à educação do futuro. Trad. Catarina Eleonora F. da Silva e Jeanne Sawaya. São Paulo: Cortez; Brasília, DF: Unesco, $2000 \mathrm{a}$.

MORIN, E. O Método 3: o conhecimento do conhecimento. Trad. Juremir Machado da Silva. Porto Alegre: Sulina, 1999.

MORIN, E. Meus demônios. Trad. Leneide Duarte e Clarisse Meireles. Rio de Janeiro: Bertrand Brasil, 1997.

MORIN, E.; CIURANA, E. R.; MOTTA, R. D. Educar na era planetária: o pensamento complexo como método de aprendizagem pelo erro e incerteza humana. Trad. Sandra Trabucco Valenzuela. São Paulo: Cortez, 2003.

MORIN, E.; KERN, A. B. Terra-Pátria. Trad. Paulo Neves da Silva. Porto Alegre: Sulina, 2011.

NAIR, S.; MORIN, E. Uma política de civilização. Trad. Armando Pereira da Silva. Lisboa: Instituto Piaget, 1997.

VELOSO, C. Fora da ordem. CD Circuladô, Gravadora: Elektra Nonesuch, 1991. 